\title{
Endo-first Approach for Peripheral Vascular Disease: The First Fifty Cases of a New Clinic
}

\author{
(D) Cihan Yücel, (1) Serkan Ketenciler, (1) Mete Gürsoy, (1) ilhan Sanisoğlu, (D) Nihan Kayalar \\ İstanbul Okmeydanı Training and Research Hospital, Clinic of Cardiovascular Surgery, Istanbul, Turkey
}

\section{Abstract}

Objective: In recent years, endovascular and hybrid therapies have come to the forefront in the treatment of peripheral arterial disease (PAD) instead of open surgical treatment. In this study, we aimed to present the results of endovascular and hybrid treatments performed in our newly established clinic.

Methods: The data of the patients, who were diagnosed as PAD and treated with endovascular and hybrid methods, were retrospectively analyzed and 50 patients were included in the study. Patients were classified according to the Fontaine classification and patients with Fontaine $2 \mathrm{~B}$ or higher underwent interventional or hybrid treatment.

Results: The majority of the patients were male (96\%) and mean age of the patients was $62.89 \pm 9.01$ years. Twelve patients (24\%) had ischemic ulcers (Fontaine 4), 32 patients (64\%) had claudication (Fontaine 2B) and six patients (12\%) had rest pain (Fontaine 3). Thirty-four patients (68\%) underwent endovascular intervention and 16 (32\%) underwent hybrid treatment procedures. In 38 patients (76\%) with complaints of Fontaine class $2 \mathrm{~B}$ or 3 before the intervention, symptoms regressed to Fontaine class 1 after the procedure. The mean ankle-brachial index values of the extremities with lesions increased from $0.44 \pm 0.30$ to $0.85 \pm 0.17$ on the first postoperative day.

Conclusion: In conclusion, endovascular and hybrid interventions provide satisfactory results in high-risk patients with PAD for both the salvage of extremities and the improvement of symptoms. We believe that endovascular interventions will provide less invasive and safer revascularization in patients with higher comorbidity rates in the future.

Keywords: Peripheral arterial disease, endovascular treatment, hybrid treatment

\section{INTRODUCTION}

The prevalence of peripheral arterial disease (PAD) in the population over 50 years of age is 13\% and the frequency of symptomatic PAD in the same population is reported to be $5 \%$ (1). When its effects on quality of life and pharmacoeconomic criteria are evaluated, the true importance of the disease becomes more evident. The expected 5-year mortality rate in male patients with PAD is similar to prostate and colon cancer (2). This data alone reveals the severity of the disease.

In addition to limiting daily activities and decreasing the quality of life associated with reduced walking range and intermittent claudication, PADs may also lead to mortality and morbidity due to rest pain, ischemic ulcers, prolonged treatment and minor and major amputations. For this reason, early diagnosis of the disease, identification and prevention of risk factors, initiation of appropriate medical treatment, and timely and effective revascularization of symptomatic patients are necessary. The TransAtlantic Inter-Society Consensus II (TASC II) study group has reported that the frequency of amputation in PAD was between 12 and 50 per 100,000 (3). Many studies have demonstrated that the increased rate of revascularization, especially in the last decade of life, creates a significant reduction in the rate of amputation. According to the data from United States, endovascular interventions, which have increased in the last 10 years, reduced the need for amputation and open surgery by about $50 \%$ (4). Nowadays, the increasing experience of percutaneous interventional treatments has provided significant benefits for rapid, effective and total revascularization, and therefore many authors now prefer the "endo-first" approach (5). Endovascular interventional treatments offer advantages in symptomatic recovery, graft patency rates, rapid recovery and 
rapid return to daily life both as a sole treatment and as a part of hybrid approaches.

In this study, our aim was to present early results of our first 50 patients who underwent endovascular or hybrid peripheral vascular interventions at Okmeydanı Training and Research Hospital, Clinic of Cardiovascular between January and July 2018.

\section{METHODS}

In this study, data from the clinical database were analyzed retrospectively. Our first 50 patients who have underwent endovascular or hybrid interventions for peripheral vascular disease were evaluated for risk factors, comorbid conditions, early patency, mortality and morbidity. All patients underwent vascular physical examination and ankle-brachial indexes (ABI) were measured at the initial evaluation. For patients with an $A B I$ of less than 0.9 , computer-assisted tomographic angiography examinations were performed depending on the severity of arterial Doppler results or symptoms and the preference of the clinician. Patients were classified according to the Fontaine classification and patients with Fontaine 2B or higher underwent interventional or hybrid treatment. Endovascular or hybrid treatment was considered and applied as the first-line intervention for high-risk patients with severe comorbidity. All patients participating in the study were informed about the study and their consents were obtained. Ethics committee approval was not taken since the study was retrospective in design.

\section{Statistical Analysis}

Statistical analyses were performed using the SPSS package program (SPSS Inc., Chicago, IL, USA) version 16.0. Continuous variables were expressed as mean \pm standard deviation and categorical variables were expressed as number and percentage.

\section{Surgical Technique}

Endovascular interventions were carried out under local anesthesia and hybrid interventions were carried out under either general anesthesia or local anesthesia and peripheral nerve block. In cases where a percutaneous approach was performed, arterial puncture site was determined using ultrasonography and punctures were made directly through surgical incision areas in hybrid interventions. Ipsilateral antegrade approach was used preferably where appropriate, and the contralateral approach was also used when necessary. Balloon angioplasty was selected as endovascular technique and atherectomy was used as a combined procedure in cases where this approach was deemed necessary. The angioplasty technique included predilatation with a standard balloon suitable for vessel size and completion of angioplasty using a drug-coated balloon $1 \mathrm{~mm}$ larger than the first one. Atherectomy was added to the procedure for patients with total occlusions and diffuse lesions with advanced calcification $(>10 \mathrm{~cm})$, and the sequence of the procedure was planned as predilatation, followed by atherectomy and balloon angioplasty. The stenting procedure of arteries was preserved for patients with complications or severe recoil.

\section{RESULTS}

This study included 50 patients who had undergone endovascular or hybrid peripheral vascular interventions at Okmeydanı Training and Research Hospital between January and July 2018. The majority of the patients were male (96\%) and only two (4\%) were female. The age range of the patients was 46-74 years and the mean age was $62.89 \pm 9.01$ years. The most prevalent risk factor was smoking $(88 \%)$, followed by diabetes (56\%) and hypertension (40\%) (Table 1). Twelve patients (24\%) had ischemic ulcers (Fontaine 4), 32 (64\%) had claudication (Fontaine 2B) and six (12\%) had rest pain (Fontaine 3). The mean $A B I$ values of the extremities with lesions were $0.44 \pm 0.30$. Thirtyfour patients (68\%) underwent endovascular interventional treatment and 16 patients (32\%) underwent hybrid treatment procedures. Detailed data on procedures and arterial sites of intervention are given in Table 2 and 3. In 38 patients (76\%) with complaints of Fontaine class $2 \mathrm{~B}$ or 3 before the intervention, symptoms regressed to Fontaine class 1 after the procedure. Minor amputations were performed in two patients (24\%) out of 12 patients with Fontaine 4 classification. The mean $A B I$ of the affected extremities measured on the first postoperative day was $0.85 \pm 0.17$. During post-operative follow-up, early occlusion compelled the placement of a new graft in one patient with cross-femoral bypass graft. Balloon angioplasty was applied to the superficial femoral artery in the same operation. Due to seroma caused by inguinal incision, this patient required a long-term in-patient follow-up and vacuum assisted closure. No culture positive wound site infection was observed in any patient. After being discharged, one patient underwent primary coronary angioplasty due to inferior myocardial infarction.

\begin{tabular}{|l|l|l|}
\hline Table 1. Preoperative risk factors of patients \\
\hline Risk factor & Number $(\mathbf{n})$ & Percent (\%) \\
\hline Hypertension & 20 & 40 \\
\hline Diabetes & 28 & 56 \\
\hline Hyperlipidemia & 10 & 20 \\
\hline Coronary artery disease & 16 & 32 \\
\hline Smoking & 44 & 88 \\
\hline Chronic renal failure & 4 & 8 \\
\hline
\end{tabular}




\begin{tabular}{|c|c|}
\hline Procedure & $\begin{array}{l}\text { Number of } \\
\text { patients }\end{array}$ \\
\hline Left ATA angioplasty & 3 \\
\hline Right ATA angioplasty & 4 \\
\hline Left SFA angioplasty & 6 \\
\hline Right SFA angioplasty & 6 \\
\hline Left CIA angioplasty & 3 \\
\hline Right CIA angioplasty & 3 \\
\hline Right SFA angioplasty + right ATA angioplasty & 4 \\
\hline Left SFA angioplasty + left ATA angioplasty & 5 \\
\hline
\end{tabular}

\begin{tabular}{|l|l|}
\hline $\begin{array}{l}|l| \\
\text { Table 3. Data on hybrid procedures and arterial sites of } \\
\text { intervention }\end{array}$ & 2 \\
\hline Right femoro-popliteal bypass + right ATA angioplasty & 4 \\
\hline Left femoro-popliteal bypass + left ATA angioplasty & 2 \\
\hline Left CFA endarterectomy + left SFA angioplasty & 1 \\
\hline $\begin{array}{l}\text { Left popliteal artery safen vein interpozition + left ATA } \\
\text { angioplasty }\end{array}$ & 2 \\
\hline Left CIA angioplasty + cross femoral bypass & 1 \\
\hline Left SFA angioplasty + cross femoral bypass & 2 \\
\hline Left CIA angioplasty + left femoro-popliteal bypass & 1 \\
\hline Right CIA angioplasty + CFA endarterectomy & 1 \\
\hline Left axillo-femoral bypass + left ATA angioplasty & \\
\hline $\begin{array}{l}\text { ATA: Anterior tibial artery, SFA: Superficial femoral artery, CIA: Common iliac artery, } \\
\text { CFA: Common femoral artery }\end{array}$ & \\
\hline
\end{tabular}

No mortality or acute renal insufficiency was observed in any patient in this study. The mean length of hospitalization was $1.8 \pm 0.63$ days.

\section{DISCUSSION}

In parallel to the previously reported researches in the literature, this retrospective data analysis showed that the endovascular interventional and hybrid treatment methods carried out in our clinic provided successful results. Despite not being a prospective trial, we believe that this study is valuable as it reflects the early experiences of a newly established clinic. Throughout the world, the learning process of cardiovascular surgeons for percutaneous angiographic interventions is still going on in parallel to other percutaneous interventional methods, and it can be predicted that this increase in experience will be more successful and will provide more permanent results when combined with experience in vascular surgeries. Hybrid interventions are one of the most important options in the treatment of complex patients and the frequency of such treatments is increasing steadily in our clinic.
It is estimated that over 30 million people in the world suffer from PAD. In the general population, reports verify that the prevalence of PAD is $17 \%$ in women and $20 \%$ in men over 65 years of age (6).

Along with the developments in technology, endovascular interventions have become widespread in the treatment of arterial diseases. According to TASC II report published in 2007, lesions in the arteries of lower extremities are classified as type A, B, C and $D$ based on the shape and extent of the lesions. According to the current consensus, endovascular interventions are preferred for type A lesions and surgical interventions are preferred for type D lesions. For type B and type C lesions, endovascular or surgical procedures may be selected based on the status of the patient and other concomitant diseases. However, the general recommendation is to prioritize endovascular methods for type B lesions and surgical interventions for type $C$ lesions (7). While the subject of selection of endovascular or surgical interventions for different patients is still a matter of discussion, 2017 European Society for Cardiology/European Society for Vascular Surgery PAD guideline did not employ the TASC II classification and suggested, with a class I indication, endovascular approaches as primary preference for the revascularization of aortoiliac diseases with obstructive lesions shorter than $5 \mathrm{~cm}$. On the other hand, for patients with aortoiliac occlusions and no severe comorbidities, aorto-bi-femoral bypass is recommended as class I indication. It is also emphasized that endovascular interventions should be used as first strategy and as class I indications for patients with serious comorbidities and long and/or bilateral aortoiliac lesions. For aortoiliac lesions that extend to the common femoral artery, hybrid approach (iliac stenting + femoral endarterectomy/ bypass) was recommended with class Ila indication for the first time (8). For femoropopliteal arterial obstructions/occlusions with short lesions $(<25 \mathrm{~cm})$, endovascular treatment was suggested with class I indication, and surgical treatments with autologous vein grafts were suggested as class I indication for long $(\geq 25 \mathrm{~cm}$ ) lesions (8). Primary and secondary patency rates of angioplasty and stenting procedures in aortoiliac regions are high. In short lesions $(<5 \mathrm{~cm})$, post-angioplasty primary patency was $64.5 \%$ and secondary patency was $81.8 \%$ (9). There are various publications that report $85 \%$ prevalence rate of critical leg ischemia in patients with below the knee lesions. In these series, leg salvage rates with angioplasty were found to be between $80-90 \%$ (10). These data suggest that the most up-todate approach seems to be "endo-first" for PADs that require interventions. 
Left common iliac artery (CIA) angioplasty was performed in two patients with severe bilateral iliac disease, followed by a cross-femoral bypass because only one iliac artery was suitable for angioplasty. Due to severe comorbid conditions, this hybrid approach was preferred in these cases instead of aortobifemoral bypass grafting. Since three patients had aortoiliac disease along with long segment $(>25 \mathrm{~cm})$ femoro-popliteal disease, two patients had femoro-popliteal bypass after aortoiliac stenting and one patient had a cross femoral bypass in conjunction with femoro-popliteal angioplasty. In the other six patients who had distal disease besides femoro-popliteal lesions, the hybrid approach included femoro-popliteal bypass grafting and distal angioplasty in order to increase both inflow and outflow to the distal extremity. The improved symptoms and ABI levels of these patients suggest that endovascular interventions are effective in complex peripheral vascular disease and that they may be used in conjunction with open surgery in cases that sole endovascular approaches are not sufficient.

Endovascular interventions were performed alone in 34 patients (68\%). Isolated angioplasty was applied to the anterior tibial artery in seven patients (14\%), superficial femoral artery in 12 patients (24\%) and CIA in six patients (12\%). Simultaneous angioplasties to both superficial femoral and anterior tibial arteries were performed in nine patients (18\%). The procedural failure was observed in four patients (11.76\%), and endovascular intervention was re-applied and became successful in three of these patients. In the remaining patient, repeat revascularization was not considered and he was followed-up medically. These results show that procedural success rates of endovascular procedures are sufficient even in high-risk patients and repeat procedures may prove successful results in most patients.

\section{CONCLUSION}

In conclusion, endovascular and hybrid interventions provide satisfactory results in high-risk patients with PAD for both the salvage of extremities and the improvement of symptoms. In cases where endovascular approaches alone are not enough, hybrid approaches may help to provide complete revascularization of affected extremities. We believe that the increased angiography experience of cardiovascular surgeons in the following years will help improve endovascular interventions to provide less invasive and safer revascularization in patients with higher rates of comorbidity.

\section{Ethics}

Ethics Committee Approval: Retrospective study.

Informed Consent: Retrospective study.

Peer-review: External and interal peer-reviewed.

\section{Authorship Contributions}

Surgical and Medical Practices: C.Y., Concept: N.K., Design: M.G., Data Collection or Processing: S.K., Analysis or Interpretation: I.S., Literature Search: C.Y., Writing: C.Y.

Conflict of Interest: No conflict of interest was declared by the authors.

Financial Disclosure: The authors declared that this study received no financial support.

\section{REFERENCES}

1. Crawford F, Welch K, Andras A, Chappell FM. Ankle brachial index for the diagnosis of lower limb peripheral arterial disease. Cochrane Database Syst Rev 2016;9:CD010680.

2. TKDCD Periferik arter ve ven hastalıkları tedavi kılavuzu-2008;s:2.

3. Norgren L, Hiatt WR, Dormandy JA, Nehler MR, Harris KA, Fowkes FG. Intersociety consensus for the management of peripheral arterial disease (TASC II). J Vasc Surg 2007;45:5-67.

4. Paulus N, Jacobs M, Greiner A. Primary and secondary amputation in critical limb ischemia patients: different aspects. Acta Chir Belg 2012;112:251-4.

5. Lee JT. Could the endo-first strategy really be better? Arch Surg 2012;147:846

6. Welten GM, Schouten O, Chonchol M, Hoeks SE, Bax JJ, Van Domburg RT, et al. Prognosis of patients with peripheral arterial disease. J Cardiovasc Surg (Torino) 2009;50:109-21.

7. Norgren L, Hiatt WR, Dormandy JA, Nehler MR, Haris KA, Fowkes FG. Intersociety consensus for the management of peripheral arterial disease (TASC II). Eur J Vasc Endovasc Surg 2007;33: P1-75.

8. Aboyans V, Ricco JB, Bartelink MEL, Björck M, Brodmann M, Cohnert T, et al 2017 ESC Guidelines on the Diagnosis and Treatment of Peripheral Arterial Diseases, in collaboration with the European Society for Vascular Surgery (ESVS): Document covering atherosclerotic disease of extracranial carotid and vertebral, mesenteric, renal, upper and lower extremity arteriesEndorsed by: the European Stroke Organization (ESO)The Task Force for the Diagnosis and Treatment of Peripheral Arterial Diseases of the European Society of Cardiology (ESC) and of the European Society for Vascular Surgery (ESVS). Eur Heart J 2018;39:763-816

9. Abello N, Kretz B, Picquet J, Magnan PE, Hassen-Khodja R, Chevalier J, et al. Long-term results of stenting of the aortic bifurcation. Ann Vasc Surg 2012;26:521-6

10. Van Overhagen H, Spiliopoulos S, Tsetis D. Below the-knee interventions, Cardiovasc Intervent Radiol 2013;36:302-1. 